\title{
DIREITOS HUMANOS, DESCOLONIALISMO E A CONTRIBUIÇÃO BRASILEIRA PARA (RE) INTERPRETAÇÃO DOS CONCEITOS DE ASILO E DE REFÚGIO
}

\author{
HUMAN RIGHTS, DECOLONIALISM AND THE BRAZILIAN \\ CONTRIBUTION TO (RE) INTERPRETATION OF \\ ASYLUM AND REFUGE CONCEPTS
}

\author{
Eduardo Biacchi Gomes* \\ Ane Elise Brandalise ${ }^{* *}$
}

\begin{abstract}
Resumo: O presente artigo tem por fim analisar, sob a ótica do descolonialismo, os avanços da legislação brasileira em relação aos critérios para concessão do asilo. Para tanto, parte-se do próprio conceito de descolonialismo e a sua aplicabilidade dentro do contexto atual para construção dos Direitos Humanos na América Latina, de forma a cotejar com a nova legislação brasileira em relação aos critérios para fins de concessão de asilo e de refúgio. Por fim, de forma a demonstrar a importância do tema frente ao Sistema Interamericano de Proteção aos Direitos Humanos, questionar-se-á quanto a possibilidade de referidos temas serem analisados por parte da Corte Interamericana de Direitos Humanos (Corte IDH).

Palavras-chave: Direitos Humanos; Descolonialismo; Asilo; Refúgio; Lei de Imigrantes.
\end{abstract}

\begin{abstract}
The purpose of this article is to analyze, from the point of view of decolonialism, the advances of Brazilian legislation in relation to the criteria for granting asylum. In order to do so, it is based on the very concept of decolonialism and its applicability within the current context for the construction of Human Rights in Latin America, in order to compare with the new Brazilian legislation in relation to the criteria for granting asylum and refuge. Finally, in order to demonstrate the importance of the issue in the Inter-American System for the Protection of Human Rights, it will be questioned whether the above-mentioned issues can be analyzed by the Inter-American Court of Human Rights.
\end{abstract}

Keywords: Human Rights; Decolonialism; Asylum; Refuge; Law of Immigrants.

\footnotetext{
* Estágio de Pós-doutoramento na Universidade Federal do Rio de Janeiro, com estudos realizados na Universidade de Barcelona; Pós-doutorado do Programa de Mestrado em Direitos Humanos e Políticas Públicas da Pontifícia Universidade Católica do Paraná; Doutor em Direito pela Universidade Federal do Paraná; Professor Permanente do Programa de Mestrado em Direito do UniBrasil; Professor colaborador do Programa de Mestrado em Direito da Uninter e Professor Titular da Pontifícia Universidade Católica do Paraná. Contato: ebgomes@me.com.

** Possui graduação em Direito pela Pontifícia Universidade Católica do Paraná - PUCPR (2012); aluna bolsista PIBIC-PUCPR (2008-2010) e graduação em Relações Internacionais pela Uninter (2012-2015); aluna bolsista de pesquisa científica - Uninter (2013-2014). Mestre em Direitos Fundamentais e Democracia no Centro Universitário Autônomo do Brasil - UniBrasil (2015-2017) e pesquisadora do Grupo PATRIAS, cadastrado no CNPQ. Contato: anebrand@gmail.com.
} 


\section{INTRODUÇÃO}

Nos últimos anos os países latino-americanos têm atravessado períodos grandes desafios, principalmente no que diz respeito a manutenção de conquistas sociais, aplicação dos Direitos Humanos e a própria consolidação da democracia. Os Estados, considerados como democracias foram constituídos nos moldes de democracias republicanas, com valores próprios do eurocentrismo. $\mathrm{O}$ mesmo diga-se em relação à própria construção e observância dos Direitos Humanos, notadamente porque a maioria dos países ratificaram os principais tratados sobre o tema.

Neste sentido, o próprio Sistema Interamericano de Proteção aos Direitos Humanos contribui enormemente para consolidação da democracia e a aplicação dos Direitos Humanos dentro dos países que o integram. Observa-se, neste sentido, enormes avanços dentro da Corte Interamericana de Proteção aos Direitos Humanos que, em última instância, é a última e a principal interprete do Pacto de San José da Costa Rica, 1969.

Certo é que não se pode negar a importância e a própria realidade dos valores e da própria história da Europa dentro de nossa cultura e que influenciou, diretamente, para construção das democracias latino-americanas. Todavia, uma questão a ser enfrentada dentro do presente artigo é a seguinte: através de valores próprios da cultura latino-americana, torna-se possível evoluir em critérios e conceitos seculares e construídos pela cultura europeia, de forma a evoluir na aplicação dos Direitos Humanos?

Como forma de melhor demonstrar a tese, o trabalho expõe ao leitor que os Direitos Humanos estão em constante evolução e, consequentemente, permitem mais de uma interpretação, sempre com o intuito de proteger a pessoa humana e que valores préconcebidos e construídos por uma cultura não podem ser simplesmente transpostos em outra cultura.

Tratar-se-á aqui e como forma de fundamentar nossos estudos, do descolonialismo, que busca a construção de valores identitários próprios latinoamericanos, naturalmente sem romper com conceitos pré-existentes, aqueles advindos dos valores dos colonizadores. Neste mesmo sentido, ver-se-á como a nova lei brasileira de imigração contribui para uma melhor compreensão e aplicação dos conceitos de asilo e de refúgio.

Por fim, de forma a demonstrar a dimensão do tema e dentro das considerações finais, o trabalho evidenciará a tese central, comprovando que dentro da R. Fac. Dir. UFG, v. 42, n. 2, p.141-155, maio/ago. 2018 
Direito, devir negro e conflito ecológico distributivo

própria Corte Interamericana de Proteção aos Direitos Humanos, existe uma atuação proativa na aplicação dos Direitos Humanos. Aqui trabalho mencionará a Opinião Consultiva do Equador, ainda pendente de análise, sobre a questão do asilo e do refúgio.

\section{DESCOLONIALISMO E OS DIREITOS HUMANOS}

Para grande parte da doutrina, os Direitos Humanos são aqueles consolidados ao longo de grandes processos históricos, como as Revoluções Francesa, 1789, dos Estados Unidos da América, 1787 e que culminaram com os fatos que ocorreram na Segunda Guerra Mundial, em que se experimenta a elevação do indivíduo enquanto sujeito de direito internacional. A título de exemplo: Tribunal de Nuremberg e de Tóquio, Declaração Universal dos Direitos Humanos de 1948 e os próprios sistemas regionais de proteção aos Direitos Humanos.

Longe de querermos traçar outra linha de raciocínio, dentro dos valores duramente consolidados pela humanidade, ao longo da história em relação aos Direitos Humanos, nosso objetivo é apresentarmos o conceito de descolonialismo, com a finalidade de demonstrar ao leitor a possibilidade de agregarmos valores próprios, latinoamericanos, aos direitos do homem.

Para situar o leitor e embora não seja objeto central de nossa pesquisa, importante mencionarmos que teorias clássicas que guiaram a sociedade internacional e os seus respectivos Estados, como liberalismo, realismo e marxismo clássico, ou mesmo teorias novas como a do construtivismo, guardam uma relação particular com a Europa, vez que todas elas foram concebidas na Europa, tanto porque foram pensadas para solucionar os problemas existentes nessas regiões centrais quanto porque serviram para basear um discurso hegemônico e dominante em detrimento de outros Estados.

Como contraponto às teorias hegemônicas e dominantes do eurocentrismo surgem as abordagens da teoria pós colonialista, antes ignoradas ao longo da história e afastadas do campo político, o que veio a ser gradualmente mudado, especialmente no período do entre e do pós-Guerra-Fria.

Com efeito, as visões clássicas de mundo modificaram-se substancialmente, tanto é verdade que teorias pós-colonialistas passaram a fazer parte dos estudos sobre o tema e, consequentemente, conquistaram a América Latina, com sua forma revisionista do discurso até antes predominante de norte/sul e, ao mesmo tempo, com a ideia maior de reconsiderar os processos históricos, jurídicos e políticos existentes em cada país ${ }^{1}$. 
Mais especificamente, na América Latina, sob um viés econômico e político, importante citarmos pensadores importantes, como Eduardo Galeano, que demonstra a sua visão pós-colonialista em seu livro "As veias abertas da América Latina". Nesse sentido, já no início da obra o autor dá conta de demonstrar um dos pontos estudados pelo pós-colonialismo: a necessidade de revisitar toda a história da região latino-americana, marcada por grande violência (GALEANO, 1971).

Outrossim, ainda sobre o tema neocolonialismo na América Latina, importante o doutrinador Antônio Carlos Wolkmer, que em seus estudos perpassa por questões relacionadas ao pluralismo, cultura e identidade e os considera como elementos necessários para o Direito latino-americano levar em conta. Em suas pesquisas, o doutrinador também nota que o momento em que se vive é diferenciado, e impõe um novo olhar, um olhar que leve em conta fatores próprios e que não seja teorizado por meio de estudos eurocêntricos (WOLKMER, 1994).

Mas, afinal, qual o problema das perspectivas pós colonialistas? Ora, uma das críticas que se coloca a tais vertentes teóricas é a de que os países semiperiféricos e periféricos (assim chamados pela perspectiva pós-colonialista os países em desenvolvidos e desenvolvidos) não vivem insulados, e estão em constante interdependência complexa.

Neste sentido, há de se mencionar o chamado diálogo intercultural, propugnado por autores como Raimon Panikkar (2004). Assim, torna-se necessário, através de um discurso dialético, repensarmos os valores do Direito Internacional e, consequentemente dos Direitos Humanos, a partir das bases construídas pelo eurocentrismo e, sem negar os seus valores, rediscutir o papel da América Latina dentro do contexto.

Isso, naturalmente nos levará a descobrir valores próprios e inerentes a cultura latino-americana, como elementos e valores que deverão ser agregados em nossa sociedade e que certamente diferem dos valores do eurocentrismo.

Dentro de nossa linha de pesquisa cabe um questionamento a ser enfrentado: dentro das antigas colônias da América Latina, como se buscar o referido diálogo entre a cultura europeia e a latino-americana? Longe de se buscar o rompimento com os valores históricos e seculares da cultura europeia, visto que somos parte dela, nosso objetivo é trazer elementos de investigação que possam fundamentar o chamado diálogo intercultural.

Neste sentido, cumpre destacarmos os ensinamentos de Walter D. Mignolo, o qual, utilizando-se dos ensinamentos de Aníbal Quijano, afirma que em realidade o que R. Fac. Dir. UFG, v. 42, n. 2, p.141-155, maio/ago. 2018 
Direito, devir negro e conflito ecológico distributivo

se busca é a chamada "desobediência epistêmica". Para ele, a teoria do descolonialismo (ou pós-colonialismo) não tem por objetivo o rompimento abrupto e definitivo dos valores europeus, mas por outro lado uma (re)afirmação dos valores latino-americanos, de forma a se buscar uma "identidade em política", assim definida pelo autor:

E a identidade em política é relevante não somente porque a política de identidade permeia, como acabei de sugerir, todo o espectro de identidades sociais, mas porque o controle da política de identidade reside, principalmente, na construção de uma identidade que não se parece como tal, mas como a aparência "natural" do mundo (MIGNOLO, 2007).

Assim, para concretização dos objetivos e conquista da identidade em política, a via defendida por Mignolo é a interculturalidade, conceituada como:

(...) um diálogo intenso que é o diálogo do futuro entre a cosmologia não ocidental (...) e ocidental (...). Aquí você acha exatamente a razão por que a cosmologia ocidental é "universal" (...) e imperial enquanto os pensamentos e as epistemologias descoloniais tiveram que ser pluri-versais: aquilo que as línguas e as cosmologias não ocidentais tinham em comum é terem sido forçadas a lidar com a cosmologia ocidental (mais uma vez, grego, latim e línguas européias imperiais modernas e sua epistemologia). (MIGNOLO, 2007).

No ponto, defende-se, aqui, que é dentro da questão da interculturalidade que os Direitos Humanos devem ser analisados, sem abandonarmos as ideias, conceitos e construções clássicas e tradicionais da cultura europeia, que inclusive fazem parte da cultura latino-americana, mas considerando tais valores e ideias como o conjunto de maneiras aptas a buscar elementos próprios à evolução dos Direitos Humanos na América Latina. O nosso desafio, portanto, será o de apontar para os desafios a serem perseguidos dentro deste contexto e demonstrar ser possível tais afirmações.

Neste particular, a pesquisa trabalhará com os conceitos de refúgio e de asilo, para nos tópicos seguintes, verificarmos a contribuição do direito brasileiro em relação ao tema, sob a perspectiva da nova lei de imigrantes, assim como a contribuição da Corte Interamericana de Direitos Humanos, ora vislumbrada sob o prisma da Opinião Consultiva apresentada pelo Equador.

Longe de elaborarmos um estudo aprofundado sobre ambos os institutos, cumpre destacarmos que o asilo é construção direta do direito latino-americano, previsto originariamente no Tratado de Direito Penal Internacional de Montevidéu de 1889 e posteriores convenções sobre o tema². 
Destarte, trata o asilo de um instituto de caráter regional e aplicado dentro do continente americano ${ }^{3}$, ao passo que o instituto do refúgio é de caráter universal, sendo construção europeia.

Nesse sentido, entenda-se por migração um termo muito mais amplo, capaz de abranger as mais diversas razões para mudanças do local em que se vive, enquanto por refúgio compreenda-se o status jurídico protegido por normas internacionais de um direito internacional especializado, sendo composto por pessoas "que estão fora de seus países de origem por fundados temores de perseguição, conflito, violência ou outras circunstâncias que perturbam seriamente a ordem pública" (ALTO COMISSARIADO, 2017). E, ainda, de forma mais restrita, há o asilo, de existência regional, que tem sua prática limitada à questão de perseguição política (JUBILUT, 2007).

Mais especificamente, no âmbito interamericano:

\begin{abstract}
Habida cuenta que los instrumentos regionales en materia de derechos humanos consagran el derecho de solicitar y recibir asilo, el derecho de no devolución y la prohibición de la expulsión colectiva, es claro que también protegen y deben ser utilizados para proteger a los refugiados y otras personas necesitadas de protección internacional en la región. Igualmente, la interpretación del artículo 22.7 de la Convención Americana sobre Derechos Humanos respecto del derecho de solicitar y recibir asilo, en relación con el artículo XXVII de la Declaración Americana de Derechos y Deberes del Hombre, presupone la referencia a la Convención de 1951 y su Protocolo de 1967 sobre el Estatuto de los Refugiados (lex specialis), tal y como ya lo ha reiterado la doctrina y jurisprudencia de la Comisión Interamericana de Derechos Humanos. En consecuencia, en nuestro continente el alcance y contenido del derecho de asilo como derecho subjetivo está igualmente relacionado con el derecho internacional de refugiados, y en particular, con la Convención sobre el Estatuto de los Refugiados de 1951 y su Protocolo de 1967. (Grifo nosso) (GONZALEZ, 2008).
\end{abstract}

Há de se assinalar que em raros casos a Corte Interamericana (Corte IDH) analisou temas que versassem sobre o asilo e, muitas vezes, confunde e utiliza impropriamente os termos asilo e refúgio. Em uma das oportunidades foi no caso Família Pacheco Teneo Vs. Estado Plurinacional da Bolívia, no ano de 2013, em que houve a condenação da Bolívia, dentre outras medidas, a elaborar programas de capacitação aos seus funcionários que tenham contato com estrangeiros que venham a requerer o asilo ou o refúgio ${ }^{4}$.

No contencioso em questão, muito embora a Corte IDH reconheça ser a concessão do asilo um ato discricionário do Estado, à própria segurança do estrangeiro que faz o pedido, em caso de sua denegação, ele não pode ser remetido ao país de origem, o qual ele alega ser vítima de violações de direitos (princípio da não devolução) e que, 
Direito, devir negro e conflito ecológico distributivo

ademais, dentro do Estado no qual ele solicita o pedido, deve ter acesso a todos os meios administrativos e judiciais internos possíveis:

197. La Corte reitera que el derecho de buscar y recibir asilo establecido en el artículo 22.7 de la Convención Americana no asegura que deba reconocerse el estatuto de refugiado a la persona solicitante, pero sí que su solicitud sea tramitada con las debidas garantías.

198. En este caso, en relación con la denegatoria de la solicitud de asilo, el Estado violó los derechos a las garantías judiciales, a buscar y recibir asilo, el principio de no devolución, y el derecho a la protección judicial, reconocidos en los artículos 8, 22.7, 22.8 y 25 de la Convención Americana, en relación con el artículo 1.1 del mismo instrumento, en perjuicio de Rumaldo Juan Pacheco Osco, Fredesvinda Tineo Godos, Frida Edith, Juana Guadalupe y Juan Ricardo, los tres de apellido Pacheco Tineo.

199. Asimismo, a efectos del presente caso, la expulsión al país de origen de los miembros de una familia en violación de las garantías mínimas de debido proceso, y con conocimiento de que podían contar con protección como refugiados de un tercer país, resulta incompatible con el derecho de buscar y recibir asilo y con el principio de no devolución, reconocidos en los artículos 22.7 y 22.8 de la Convención Americana. Además, el Estado es responsable por la violación del derecho a ser oído con las debidas garantías en un procedimiento administrativo que culminó con la expulsión de la familia, así como a la protección judicial, en los términos de los artículos 8.1 y 25 de la Convención Americana, en relación con el artículo 1.1 del mismo instrumento, en perjuicio de Rumaldo Juan Pacheco Osco, Fredesvinda Tineo Godos, Frida Edith, Juana Guadalupe y Juan Ricardo, los tres de apellido Pacheco Tineo (CORTE INTERAMERICANA..., 2013).

Para além do direito internacional dos direitos humanos, não obstante os avanços do Sistema Interamericano de Proteção aos Direitos Humanos em relação ao tema, como forma de (re)pensar os Direitos Humanos, especialmente em relação ao instituto jurídico do asilo, vale a pena destacar que o direito brasileiro, através da nova lei de imigrantes também contribui com a referida dialética entre os valores eurocêntricos e latino-americanos, contribuindo para consolidação da proposta da "desobediência sistêmica".

Por isso mesmo, é necessário estudar essa nova lei de Imigrantes e correlacioná-la com a noção de Asilo, sem descurar da perspectiva da dialética sistêmica.

\section{NOVA LEI DE IMIGRANTES E A QUESTÃO DO ASILO SOB A PERSPECTIVA DA DIALÉTICA SISTÊMICA}

Com a emergência de se discutir o tema migrações e refúgio, está em vias de concretização no ordenamento jurídico brasileiro a Nova lei de Migrações, fruto do Projeto de Lei $\mathrm{n}^{\mathrm{o}}$ 2.516/2015, travestida com diferente nomenclatura, em que o 
estrangeiro passa a ser visto como migrante, e com diferentes perspectivas do quadro antes havido quando no advento do antigo Estatuto do Estrangeiro (Lei n ${ }^{\circ}$ 6.815/1980).

Com efeito, os dados de refúgio e migrações são alarmantes: em 2015 o número de refugiados no mundo aproximou-se de 65,3 milhões, fazendo com que $1 \mathrm{em}$ cada 113 pessoas no planeta seja solicitante de refúgio (NAÇÕES UNIDAS, 2015), sem contar outros tantos milhões que se enquadram como migrantes internacionais e internos, não obstante não se poder olvidar que no Brasil sempre houve a presença de imigrantes, os quais foram importantes atores sociais no país.

Outrossim, na análise do recebimento de tais pessoas, sejam refugiadas ou migrantes, observa-se que o tratamento por parte de certos Estados do continente europeu e, sobretudo, dos Estados Unidos, parece avultar o desprezo, a violência e a proibição para com os refugiados e migrantes, contribuindo de sobremaneira a multiplicação das violações contra direitos humanos (THE ATLANTIC, 2017).

Ora, várias são as formas de compreensão acerca da migração, mas uma delas, que não pode ficar além de uma perspectiva descolonizadora, é a de que tal aumento pode estar vinculado às próprias características do capitalismo, em que a economia dos países centrais representa um dos principais motivos para emigração, com o consequente aumento de número de países a regulamentar e até reduzir a imigração, por medo de uma invasão migratória e riscos de desemprego para os trabalhadores natos do país, conforme observa a socióloga da globalização Saskia Sassen (2005).

Diante de tal conjuntura, celebra-se o advento de uma nova lei brasileira sobre o tema migrações, já que pode ser capaz de trazer a importância da América Latina na questão de temas sensíveis como esse, que lida com a pessoa humana, questões econômicas, sociais e culturais, mas sem desconsiderar que os Estados centrais devem prezar por políticas de solidarismo.

Nesse sentido, verifica-se que a nova lei de migrações define uma série de direitos e deveres dos migrantes no Brasil, sem prejuízo do tratamento conferido ao refugiado, categoria que encontra suas bases na Lei $n^{\circ}$ 9.474/1997 e Convenção das Nações Unidas sobre o Estatuto dos Refugiados, de 1951 e sua atualização feita pelo Protocolo de 1967. Inclusive, a nova lei não deixa de prever a necessidade de observância das diretrizes de proteção internacional de direitos humanos, mormente quando na realização de políticas públicas, o que traz um grande avanço, uma vez que a questão de políticas públicas, per se, antes parecia ser algo que não muito ouvia a voz do povo (REIS, 1989), quanto menos do estrangeiro. 
Direito, devir negro e conflito ecológico distributivo

Dessa forma, a análise das políticas públicas em prol dos imigrantes, expressamente consignada em lei, traz a patente necessidade de visualizar a realidade presente, em que "a melhoria da qualidade de vida deve ser objeto essencial - se não "o" essencial - de todo exercício econômico e essa melhoria é parte integral do conceito de desenvolvimento" (SEN, 1988).

Assim, também há repúdio à xenofobia, ao racismo, à discriminação e à criminalização da imigração, consolidando um compromisso brasileiro em prol dos direitos humanos. Também há especial cuidado para com questões como tráfico de pessoas e trabalho escravo, problemas tais muitas vezes vivenciados pelos migrantes que chegam ao país sem quaisquer condições econômicas, a exemplo maior do caso dos bolivianos ilegais em São Paulo ${ }^{5}$.

Apesar do ultrapassado Estatuto de Estrangeiro ser proveniente de uma época ditatorial brasileira, foi através desse instrumento jurídico que o migrante possuía, à época, garantido os seus direitos, sendo que a lei havia disposições sobre direitos e garantias individuais do estrangeiro, tipos de vistos, formas de entrada e impedimentos, além de abordar a condição de exilado, a questão dos casos de saída compulsória (sob as formas de expulsão, extradição ou deportação), os requisitos e procedimentos para naturalização, etc., ao que à época se poderia afirmar que o Estatuto do Estrangeiro tratava-se de uma legislação avançada para seu tempo (GOMES; MONTENEGRO, 2016).

O que muda, pois, é o paradigma guiador e, consequentemente, a forma de ver e tratar o tema, agora mais humanizada. Hodiernamente, vive-se em um ordenamento jurídico diferente, guiado pela Constituição de 1988, uma das mais completas do mundo em termos de direitos fundamentais (PIOVESAN, 2009), que buscou colocar o ser humano e sua correlata dignidade como justificação de toda estruturação estatal.

A título de exemplo, se antes havia a mera figura da saída compulsória, a nova Lei impõe que se observe se a deportação, expulsão ou repatriação envolve risco à vida ou à integridade pessoal do migrante. Caso presente tal risco, as saídas não deverão ser realizadas (art. 60).

E como fica a figura do asilo na nova lei? $O$ asilo político, nas suas modalidades diplomática ou territorial, permanece com a noção de ser ato discricionário do Estado para fins de proteção à pessoa. Novidade é que não haverá concessão de asilo a aquele que tenha cometido crime de genocídio, crime contra humanidade, crime de 
guerra ou crime de agressão, em conformidade com o Estatuto de Roma, de 1988, internalizado no Brasil por meio do Decreto $n^{\circ} 4.388 / 2002$ (art. 23). No mais, dispõe a nova lei que a saída do asilado do País sem prévia autorização implica renúncia ao asilo, conforme art. 24.

A proteção ao asilo do novo documento legal brasileiro propõe uma maior abertura que anteriormente. Pode-se ver que o asilado poderá ter autorizada a residência no país, assim como o refugiado, nos termos do art. 25. Assim, o solicitante de refúgio, de asilo ou de proteção ao apátrida fará jus à residência até a obtenção de resposta ao seu pedido (art. 26, $\S 3^{\circ}$ ).

Sobre o tema, interessante que o asilo também está sendo discutido no âmbito interamericano de proteção aos direitos humanos, através da solicitação de Opinião Consultiva à Corte Interamericana, formulada pelo Equador em 15 de agosto de 2016.

No caso, o país questiona à Corte o alcance e fim do direito de asilo, à luz do Direito Internacional dos Direitos Humanos, do Direito Interamericano e do Direito Internacional. Mais especificamente, coloca em pauta as seguintes questões:

a) (...) Cabe a um Estado, grupo ou indivíduo realizar atos ou adotar uma conduta que, na prática, signifique o desconhecimento das disposições estabelecidas nos instrumentos de direitos humanos antes mencionados, incluindo o artigo 5 da Convenção de Genebra sobre o Estatuto dos Refugiados, de maneira que se atribua aos artigos 22.7 e XXVII da Convenção Americana e da Declaração Americana de Deveres e Direitos do Homem, respectivamente, um conteúdo restrito quanto à forma ou à modalidade do asilo? Quais seriam as consequências jurídicas produzidas sobre os direitos humanos e liberdades fundamentais da pessoa afetada por esta interpretação regressiva? B) Cabe a um Estado, alheio a determinada convenção sobre asilo, obstaculizar, impedir ou limitar a ação de outro Estado que é parte nesta Convenção, de maneira que não possa cumprir as obrigações e compromissos contraídos em virtude deste instrumento? Quais deveriam ser as consequências jurídicas desta conduta para a pessoa que se encontra asilada? C) Cabe a um Estado, alheio a determinada convenção sobre asilo, ou que seja parte de um regime jurídico regional distinto daquele com base no qual foi concedido o asilo, entregar a quem goza do estatuto de asilado ou refugiado ao agente de perseguição, violando o princípio de não devolução, argumentando que a pessoa asilada perde esta condição por encontrar-se em um país estranho a este regime jurídico no momento de exercer seu direito de livre mobilidade humana? Quais deveriam ser as consequências jurídicas derivadas desta conduta sobre o direito de asilo e os direitos humanos da pessoa asilada? D) Cabe a um Estado adotar uma conduta que, na prática, limite, diminua ou enfraqueça qualquer forma de asilo, argumentando para isso que não confere validez a certos enunciados de valor ético e jurídico como as leis da humanidade, os ditames da consciência pública e a moral universal? Quais deveriam ser as consequências de ordem jurídica decorrentes do desconhecimento destes enunciados? E) Cabe a um Estado negar asilo a uma pessoa que solicita esta proteção em uma de suas sedes diplomáticas aduzindo que concedê-lo significaria fazer mal-uso dos locais que ocupa a Embaixada, ou que concedê-lo desta forma significaria estender indevidamente as imunidades diplomáticas a uma pessoa sem status diplomático? Quais 
Direito, devir negro e conflito ecológico distributivo

\begin{abstract}
deveriam ser as consequências de ordem jurídica destes argumentos sobre os direitos humanos e liberdades fundamentais da pessoa afetada, tendo em conta que poderia se tratar de uma vítima de perseguição política ou de atos de discriminação? F) Cabe ao Estado asilante negar um pedido de asilo ou refúgio, ou revogar o estatuto concedido como consequência da formulação de denúncias ou do início de um processo legal contra esta pessoa, tendo indícios claros de que estas denúncias têm um motivo político e que sua entrega poderia dar lugar a uma cadeia de eventos que terminaria causando graves danos ao sujeito, isto é, a pena capital, cadeia perpétua, tortura e tratamentos cruéis, desumanos e degradantes, à pessoa reclamada? G) Considerando que os Estados possuem a faculdade de conceder asilo e refúgio com base em disposições expressas do Direito Internacional que reconhecem estes direitos baseados em razões humanitárias e na necessidade de proteger ao mais fraco e vulnerável quando determinadas circunstâncias alimentam em tais pessoas fundados temores sobre sua segurança e liberdade. (...) (CORTE INTERAMERICANA, 2016).
\end{abstract}

Considera-se que as questões colocadas pelo Equador se apresentam como uma ótima oportunidade da Corte Interamericana consolidar os direitos humanos de forma descolonializada. Até o presente momento da confecção do artigo a Corte Interamericana ainda não proferiu seu parecer, mas certamente as questões colocadas pelo Equador auxiliarão tanto ao Direito Internacional, na matéria de refúgio e de asilo, quanto no próprio fortalecimento da competência consultiva da Corte Interamericana de Direitos Humanos.

No ponto, importante lembrarmos que dentro da competência consultiva da Corte Interamericana os seus pareceres não possuem, tecnicamente, caráter vinculante como são as decisões proferidas por este Tribunal em seu caráter contencioso, mas podem ser traduzidas como diretrizes que deverão ser seguidas pelos Estados que tenham formulado determinada consulta.

A atuação consultiva da Corte Interamericana cada vez tem ganho mais destaque dentro do Sistema Interamericano de Proteção aos Direitos Humanos e muito embora as suas decisões não tenham caráter vinculante, torna-se um importante instrumento aos Estados para efetivação dos Direitos Humanos, permitindo assim, o chamado diálogo vertical entre as Cortes, a exemplo maior, de acordo com Mazzuoli, de alguns tribunais de Estados interamericanos já possuírem o hábito de fundamentar suas respectivas decisões com base nas opiniões consultivas da Corte (v.g. como ocorre na Suprema Corte da Costa Rica) (MAZZUOLI, 2013).

No caso do Brasil, percebe-se que há patente necessidade de adequação no ordenamento jurídico como um todo. Ou seja: legislação, doutrina e jurisprudência brasileira devem ser atualizadas em conformidade com os ditames protetivos de direitos humanos. 
Nessa toada, a nova legislação que versa sobre os imigrantes merece comemoração, pois se trata de um avanço sobre a temática. Por óbvio, ainda é cedo para saber as consequências que a nova lei trará ao Brasil, de modo que o trabalho aqui não se exaure por si só, pendendo de futuros estudos sobre a nova lei e seu tratamento.

Ainda assim, pode-se delinear um paralelo da nova lei brasileira com a consulta formulada pelo Equador. A resposta proferida pela Corte Interamericana, ainda que não possua, em tese, força vinculante, certamente trará consequências para como o Brasil deve encarar o instituto do asilo e, se necessário e se for o caso, adequar a nova lei para que esta não nasça já desatualizada.

\section{CONSIDERAÇÕES FINAIS: A (RE)CONSTRUÇÃO DO CONCEITO DE ASILO E DE REFÚGIO E A OPINIÃO CONSULTIVA DO EQUADOR}

Até pouco tempo atrás as perspectivas pós-colonialistas não tinham muito espaço na área jurídica e política. Contudo, após diversos acontecimentos que marcaram período de pós-Guerra Fria, a corrente descolonialista ganhou visibilidade, mormente nos países da América Latina.

Enfrentando o discurso antes hegemônico europeu e ocidental, mas sem descurar da sua importância para própria construção da América Latina atual, defende-se uma perspectiva da interculturalidade para observar os Direitos Humanos na região.

Inclusive, sobre a construção dos Direitos Humanos na América Latina, verifica-se a relevância do Direito Internacional e de institutos jurídicos como do asilo e do refúgio, que não se confundem, mas se complementam em prol da pessoa humana.

Com efeito, os temas das migrações, do asilo e do refúgio, são cada vez mais discutidos em tempos de elevado número de pessoas que se vem compelidas a deixar sua terra natal. No Brasil, a discussão culminou na formulação de uma nova lei de imigrantes, a substituir o Estatuto do Estrangeiro. Nessa nova lei de imigrantes o paradigma central muda, observando os ditames constitucionais e internacionais.

Ao seu turno, no sistema interamericano de proteção aos direitos humanos, merece destaque a atuação da Corte Interamericana de Proteção aos Direitos Humanos, que já analisou temas ligados ao asilo, como no caso contencioso da Família Pacheco Teneo Vs. Estado Plurinacional da Bolívia (2013), bem como se encontra em verificação, na sua competência consultiva, de consulta formulada pelo Equador. 
Direito, devir negro e conflito ecológico distributivo

Mais especificamente, a consulta feita pelo Equador questiona a instituição do asilo em suas diversas formas e a legalidade de seu reconhecimento como direito humano de todas as pessoas, de acordo com o princípio de igualdade e não discriminação.

Essa é uma ótima oportunidade da Corte Interamericana manifestar-se sobre o tema e consolidar uma figura jurídica que caracteriza a América Latina, por ser fruto de uma construção regional. No direito interno brasileiro, constata-se que a nova lei de imigrantes é capaz de concretizar a figura do asilo e do refúgio em conformidade com os ditames internacionais de direitos humanos e diretrizes interamericanas protetivas.

\section{REFERÊNCIAS}

ALTO COMISSARIADO DAS NAÇÕES UNIDAS PARA REFUGIADOS (ACNUR). "Refugiados" e "migrantes": perguntas frequentes. Disponível em: $<$ http://www.acnur.org/portugues/quem-ajudamos/refugiados/refugiados-e-migrantesperguntas-frequentes/>. Acesso em: 18 jan 2017.

BAENINGER, Rosana. (Org.). Imigração boliviana no Brasil. Campinas: NEPO/UNICAMP/CNPQ/UNFPA, v. 1, 2012.

BRASIL, Ministério da Justiça e Cidadania. Entenda as diferenças entre refúgio e asilo. Disponível em: <http://www.justica.gov.br/noticias/entenda-as-diferencas-entrerefugio-e-asilo>. Acesso em: 11 jan 2017.

CORTE INTERAMERICANA DE DERECHOS HUMANOS (CIDH). Familia Pacheco Tineo Vs. Estado Plurinacional de Bolivia. Excepciones Preliminares, Fondo, Reparaciones y Costas. Sentencia de 25 de noviembre de 2013. Serie C No. 272. Disponível em: <http://www.corteidh.or.cr/docs/casos/articulos/resumen_272_esp.pdf >. Acesso em: 11 jan 2017.

EQUADOR. Pedido de Parecer Consultivo à Corte. 15 de agosto de 2016. Disponível em: <http://www.corteidh.or.cr/docs/solicitudoc/solicitud_18_08_16_port.pdf>. Acesso em: 20 jan 2017.

FERNÁNDEZ, Jaime Esponda. La tradición latino-americana del asilo y la proteción internacional de los refugiados, pp. 79-125. In: FRANCO, Leonardo (coord.). EI Asilo y la protección internacional de los refugiados en América Latina. Análisis crítico del dualismo "asilo-refugio" a la luz del Derecho Internacional de los Derechos Humanos. 1a. ed. -- San José, C.R.: EDITORAMA, 2004. Disponível em: <http://www.corteidh.or.cr/tablas/a12442.pdf>. Acesso em: 11 jan 2017.

GAlEAnO, Eduardo. As veias Abertas da América Latina. Tradução de Galeano de Freitas. Rio de Janeiro, Paz e Terra, 1971. 
GOMES, Eduardo Biacchi; JULIANA, Ferreira Montenegro. Introdução aos estudos do Direito Internacional.1. ed., v. 1. Curitiba: Ed. Intersaberes, 2016.

GONZÁLEZ, Juan Carlos Murillo. La proteción internacional de los refugiados en el Sistema Interamericano de Derechos Humanos, 2008. Disponível em:

<http://www.oas.org/es/sla/ddi/docs/refugiados_sesion_especial_2008_presentacion_m urillo.pdf >. Acesso em: 11 jan 2017.

JUBILUT, Liliana Lyra. $O$ direito internacional dos refugiados e sua explicação no ordenamento jurídico brasileiro. São Paulo: Método, 2007.

MAZZUOLI, Valério de Oliveira. Comentários à convenção americana de direitos humanos: pacto de San José da Costa Rica - 4a ed. Rev., atual. e ampl. - São Paulo: Editora RT, 2014. p. 396.

MIGNOLO, Walter D. Desobediência Epistêmica. A Opção descolonial e o significado de identidade em política. Trad. Ângela Lopes Norte. Revista Gragoatá, n. 22, p. 11-41, 10 sem., 2007.

NAÇÕES UNIDAS, UNHCR. Global Trends: Forced displacement in 2015. Disponível em:

<http://www.unhcr.org/576408cd7\#_ga=1.219325020.490939995.1486061927>.

Acesso em: 18 jan 2016.

PANIKKAR, Raimon. Seria a noção de direitos humanos um conceito ocidental?. In: BALDI, César Augusto (Org.). Direitos humanos na sociedade cosmopolita. Rio de Janeiro: Renovar, 2004.

PIOVESAN, Flávia. Direitos Humanos e Direito Constitucional Internacional. 8. ed. São Paulo: Max Limonad, 2009.

REIS, Elisa Pereira. Política e políticas públicas na transição democrática. Revista Brasileira de Ciências Sociais, v. 3, p. 15-23, 1989.

SASSEM, Saskia. Regulação Imigração na idade global. A nova política. Vol. $11, \mathrm{n}^{\circ}$ 1. Parallax, 2005.

SEN, Amartya. The Concept of Development, pp. 9-26. Handbook of Development Economics, Vol I., 1988.

THE ATLANTIC. Trump has a message for poor immigrants: Get Out. The ban targeting seven Muslim-majority countries was just the beginning. February 01, 2017. Disponível em: <https://www.theatlantic.com/business/archive/2017/02/trumpimmigrants/515310/>. Acesso em: 02 fev 2016.

WOLKMER, Antônio Carlos. Pluralismo Jurídico. Fundamentos de uma nova cultura do Direito. São Paulo: Editora Alfa Ômega, 1994. 
Direito, devir negro e conflito ecológico distributivo

Artigo recebido em 03 de março de 2017 e aceito em 20 de julho de 2018

\footnotetext{
${ }^{1}$ Para saber mais, consultar: CASTRO, Thales. Teoria das Relações Internacionais. Brasília: Editora FUNAG, 2012, p. 390. Disponível em: <http://funag.gov.br/loja/download/931Teoria_das_Relacoes_Internacionais.pdf $>$. Acesso em: 05 jan 2016.
}

${ }^{2}$ BRASIL, Ministério da Justiça e Cidadania. Entenda as diferenças entre refúgio e asilo. Disponível em: <http://www.justica.gov.br/noticias/entenda-as-diferencas-entre-refugio-easilo>. Acesso em: 11 jan 2017. Para saber mais sobre o tema, consultar: FERNÁNDEZ, Jaime Esponda. La tradición latino-americana del asilo y la proteción internacional de los refugiados, pp. 79-125. In: FRANCO, Leonardo (coord.). El Asilo y la protección internacional de los refugiados en América Latina. Análisis crítico del dualismo "asilo-refugio" a la luz del Derecho Internacional de los Derechos Humanos. 1a. ed. -- San José, C.R.: EDITORAMA, 2004. Disponível em: 〈http://www.corteidh.or.cr/tablas/a12442.pdf〉. Acesso em: 11 jan 2017.

${ }^{3}$ Assim como o asilo é fruto da construção do Direito Internacional latinoamericano, também se observa, ainda que aqui não se estude sobre o assunto, doutrinas advindas da América Latina sobre questões como reconhecimento de governo, cada qual elucidando critérios e verificando formas variadas de olhar para democracia, etc.

${ }^{4}$ CORTE INTERAMERICANA DE DERECHOS HUMANOS (CIDH). Familia Pacheco Tineo Vs. Estado Plurinacional de Bolivia. Excepciones Preliminares, Fondo, Reparaciones y Costas. Sentencia de 25 de noviembre de 2013. Serie C No. 272. Disponível em: $\langle$ http://www.corteidh.or.cr/docs/casos/articulos/resumen_272_esp.pdf $>$. Acesso em: 11 jan 2017.

${ }^{5}$ Para saber mais sobre os bolivianos no Brasil, vide: BAENINGER, Rosana. (Org.). Imigração boliviana no Brasil. Campinas: NEPO/UNICAMP/CNPQ/UNFPA, v. 1, 2012. 